\title{
PLR (PLASTIC LITHIUM RECHARGEABLE) BATTERIES USING NANOSCALE MATERIALS: A CONVENIENT ELECTRICAL ENERGY POWER FOR THE FUTURE?
}

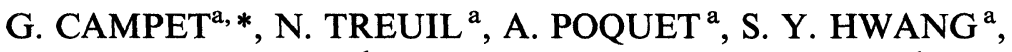 \\ C. LABRUGERE ${ }^{b}$, A. DESHAYES $^{c}$, J. C. FRISON $^{d}$, \\ J. PORTIER ${ }^{a}$, J. M. REAU ${ }^{a}$ and J. H. CHOY ${ }^{\mathrm{e}}$
}

${ }^{a}$ Institut de Chimie de la Matière Condensée de Bordeaux du CNRS, Château Brivazac, avenue du Dr. A. Schweitzer, 33608 Pessac, France;

${ }^{\mathrm{b}}$ Centre de Caractérisation des Matériaux Avancés, avenue du Dr. A. Schweitzer, 33608 Pessac, France;

${ }^{c}$ Centre National d'Etudes des Télécommunications, 38-40 rue du GénéralLeclerc, 92131 Issy-les Moulineaux, France;

${ }^{\mathrm{d}}$ Centre National d'Etudes des Télécommunications, 2 route de Trégastel, BP 40, 2301 Lanion, France;

${ }^{\mathrm{e}}$ Department of Chemistry, Center for Molecular Catalysis, College of Natural Sciences, Seoul National University, Seoul 151-742, Korea

(Received 16 December 1998; In final form 5 March 1999)

This communication describes the synthesis of: (i) non toxic and low cost nanocrystalline electrode materials which can be advantageously prepared at low temperature; (ii) highly conductive electrolyte membranes formed by the nano-encapsulation within a poly (acrylonitrile)-based polymer matrix of a solution of $\mathrm{LiPF}_{6}$ in organic solvants. The performances of rechargeable PLR (Plastic Lithium Rechargeable) batteries using the above mentioned components are presented.

Keywords: Plastic Lithium Rechargeable batteries; nanoscale materials

*Corresponding author. e-mail: campet@icmcb.u-bordeaux.fr 


\section{INTRODUCTION}

Two events deserve to be reported.

(1) The recent advances in portable electronic devices (portable computers, cellular phones, camcorders ... ) have resulted in a significant growth in the need for miniaturized power sources able to power these systems.

(2) Mankind is becoming increasingly aware of the damaging health and environmental effects of releasing nauseous gases into the atmosphere due, for instance, to the transportation in big cities. Consequently high energy and rechargeable power sources are needed for the development of long range electric vehicles leading to the improvement of the air quality [1]

These two demands have motivated the research on electrical energy systems which will be more powerful and occupy a smaller volume than conventional batteries. Obviously these new power sources must be nonpolluting and non toxic. Related to that a huge research is in progress in United States, Asia and Europe and three battery systems emerged among the most efficient ones for electric transportation application [1 5]. As quoted by Megahed S. and Scrorati B. [1], the first system uses a molten sodium anode, a sulfur-impregnated carbon felt cathode and a solid sodium ion-conducting electrolyte; the second one uses a $\mathrm{Li}-\mathrm{Al}$ anode, an iron disulfide cathode, and a molten $\mathrm{LiCl}-\mathrm{LiBr}-\mathrm{KBr}$ electrolyte. However, these two systems operate at high temperature (above $300^{\circ} \mathrm{C}$ ) [1]; they are, thereby, inappropriate for the portable electronic devices. That is not the case for the third nonaqueous systems, so called lithium batteries, which can efficiently be used at room temperature and are, therefore, intensively studied at the present time. They are based on a lithium metal or a lithium-inserted graphite as anode, a lithium-ion conducting electrolyte and a cathode material. The cathode material must be both a ionic and electronic conductor and has, generally, a structure which is opened (layered or tunneled) and can, thereby, reversibly intercalate lithium ions. Among the most efficient cathode materials let us mention transition metal dichalcogenides or oxydes such as $\mathrm{TiS}_{2}, \mathrm{LiNiO}_{2}, \mathrm{LiCoO}_{2}, \mathrm{LiMn}_{2} \mathrm{O}_{4}, \mathrm{~V}_{6} \mathrm{O}_{13}[6-30]$.

For sake of clarity the working principle of such a $\mathrm{Li}$ battery is illustrated on Figure 1. 
A non-aqueous electrolyte (ionic conductor + separator) and 2 electrodes

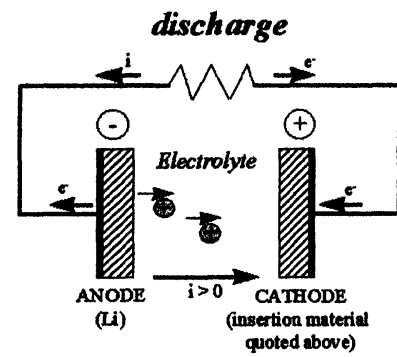

Functions :

$\checkmark$ Storage of electrical energy into chemical energy $\checkmark$ Conversion into electrical energy

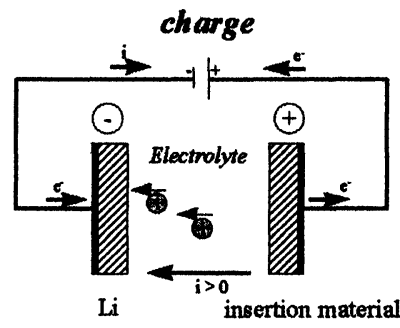

FIGURE 1 Principle of the rechargeable lithium battery.

TABLE I Performance characteristics (the three main SAFT technologies, from Internet)

\begin{tabular}{lccc}
\hline Parameters & $N i-C d$ & $N i-M H$ & Li-Ion \\
\hline Weight $(\mathrm{kg})$ & 280 & 260 & 225 \\
Specific Energy (Wh/kg) & 55 & 70 & 150 \\
Electric Vehicle & & & \\
$\quad$ Range $(\mathrm{km})$ & 100 & 130 & 200 \\
$\quad$ Maximum speed $(\mathrm{km} / \mathrm{h})$ & 95 & 110 & 120 \\
\hline
\end{tabular}

In Table I are reported the efficiencies at room temperature of $\mathrm{Li}$ batteries together with those of the more conventional systems $\mathrm{Ni}-\mathrm{Cd}$ (nickel cadmium) and $\mathrm{Ni}-\mathrm{MH}$ (nickel metal hydrure): a lithium battery having a weight of $225 \mathrm{~kg}$ is able to power an electric car for $200 \mathrm{~km}$ at a speed of $120 \mathrm{~km} / \mathrm{h}$; these performances are much lower for the $\mathrm{Ni}-\mathrm{MH}$ battery and obviously even more lower for the Ni-Cd battery.

Consequently, it appears that the lithium batteries represent (together with the fuel cells [31], which are not the subject of our communication) a leap forward in energy density compared with the conventional systems [32].

However, one guesses that a further enhancement of the performances of the electric vehicles is needed and, therefore, necessitates the production of more powerful batteries which are lighter and occupy a smaller volume than the existing ones. Moreover, regarding the portable electronic systems quoted above, one guesses also that these systems 
will become increasingly miniaturized, and this further miniaturization in portable electronics necessitates a substantial reduction in the weight and size of the lithium batteries.

From these two points of view, it will be argued hereafter that the thin and flexible lithium batteries so called PLR (Plastic Lithium Rechargeable) batteries are likely to fulfill the needs of both the electronic market and the electric transportation. In the latter event one can use, indeed, the well known roll-coating technology to get powerful PLR systems which occupy a small volume. On the other hand, in the case of the electronic market one easily guesses that the PLR batteries will be able to fit the shape of the increasingly miniaturized electronic systems and even be an integrated part of it [1].

A PLR battery can be formed by contacting a lithium metal strip, a lithium ion conducting polymeric membrane and a composite cathode membrane obtained by blending the above mentioned active lithium intercalation material with carbon and a polymer binder (Fig. 2).

$\mathrm{The}^{+} \mathrm{Li}^{+}$conducting polymer electrolyte membrane is, obviously, one of the key components of the battery since the lithium metal is indeed corroded by almost any electrolyte medium. Clearly, the instability of the lithium metal/electrolyte interface is the critical problem which remains to be circumvent in lithium batteries and, therefore, in PLR systems. A way to overcome this problem proposed so far is to replace the metal with carbon-type (coke or graphite) insertion compounds $[1,33]$. The overall process of such batteries, so called "lithium ion batteries", is illustrated on Figure 3 and can be expressed as [1,33]:

$$
\mathrm{C}_{6}+\mathrm{LiMO}_{2} \underset{\text { discharge }}{\stackrel{\text { charge }}{\rightleftharpoons}} \mathrm{Li}_{x} \mathrm{C}_{6}+\mathrm{Li}_{1-x} \mathrm{MO}_{2}
$$

\footnotetext{
- Can be fabricated in any shape and size

- Very attractive for

- the electric vehicle

- the electronic consumer market

- .......
}

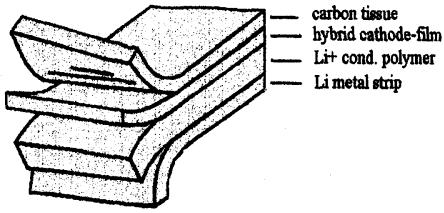

FIGURE 2 The PLR battery. 

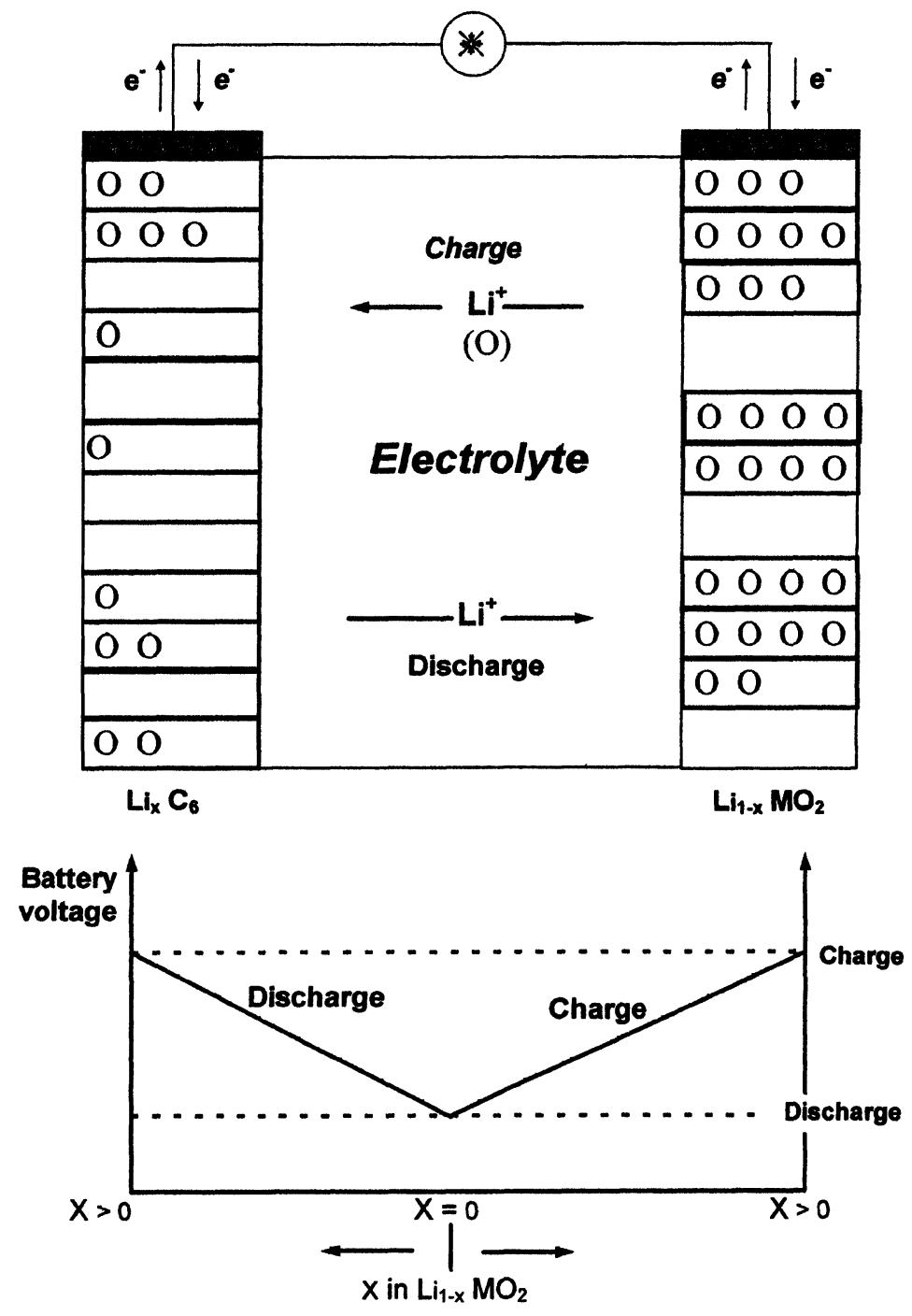

FIGURE 3 The «lithium ion battery $\gg$.

In fact, the use of $\mathrm{Li}_{x} \mathrm{C}_{6}$ as lithium source instead of $\mathrm{Li}$ metal induces losses in specific energy; moreover, voltage fluctuations, which can expand up to $1.5 \mathrm{~V}$, can occur on cycling $[34,35]$. 
In addition, an unnegligeable excess of cathode material is often required in order to get an acceptable cycle life of the "lithium ion batteries", due to the irreversible capacity in the first cycle [1].

For these reasons we have targeted our research on PLR systems which involve a lithium metal film as anode with the objective of reducing: (i) the instability of the lithium metal/electrolyte interface; (ii) the probability of short-circuit which may occur during the charging process due the dendritic growth of lithium metal on the anode. We believed that these two problems can be circumvented owing to an appropriate selection and ratio of the components forming the polymeric electrolyte-membrane.

If the polymeric electrolyte membrane is one of the two key components of the PLR system, the second one is, obviously, the electrode material.

We will show here also that nanocristalline compounds are promising electrode materials for PLR systems.

\section{CHOICE OF THE MATERIALS-EXPERIMENTAL- DISCUSSION}

\section{Choice, Preparation and Properties of the Polymeric Electrolyte Membrane}

\section{a) Choice of the Materials}

First of all let us quote that for obvious reasons the polymeric electrolyte membrane must have a room temperature conductivity as close as possible as that of the liquid lithium electrolytes so that the PLR battery will be able to operate efficiently at room temperature.

Classical examples of polymer electrolyte membranes include complexes between lithium salts (e.g., $\mathrm{LiClO}_{4}, \mathrm{LiPF}_{6} \ldots$ ) and high molecular weight polymers containing $\mathrm{Li}^{+}$coordinating atoms (e.g., poly(ethylene oxide), PEO) where oxygen is acting as the coordinating atom [36, 37].

The main problem with PLR batteries using such polymer electrolyte membranes is their inability to operate efficiently at ambient temperature due to the too low room-temperature conductivity $\left(\leq 10^{-6} \Omega^{-1} \mathrm{~cm}^{-1}\right)$ of the PEO-based electrolytes. Consequently a lot 
of research has been carried out in order to improve the room temperature performances, notably in the ACEP collaboration between Hydro-Quebec in Canada, Elf and CNRS-Grenoble in France $[38,39]$.

However, the most successful results so far have been obtained by trapping liquid electrolyte solutions into polymer cages [40]. Two distinct methods have been reported: (i) loading the liquid electrolyte into a microporous polymer; (ii) enhancing the viscosity of the liquid electrolyte by adding a soluble (in the electrolyte) polymer until a gel is achieved which can be easily spread onto Teflon moulds leading to polymeric membranes after cooling down at room temperature. The most efficient polymer additives which yield electrolyte-membranes with the required electrical and mechanical properties are poly (methyl methacrylate) (PMMA), poly(vinylidene) fluoride with hexafluoropropylene (PVDF-HFP) poly (acrylonitrile) (PAN) [41-47]. We have followed here the above mentioned approach (ii) with the aim of preventing the short-circuit events which may occur during the charging processes of the battery, as quoted above.

We have selected PAN because it is apparently the most stable versus oxidation so that it will not decompose during the charging processes of the PLR batteries [48]. Moreover the PAN has polar CN groups which can interact with the liquid electrolyte inhibiting, thereby, its departure. The liquid electrolyte consists of lithium hexafluorophosphate $\left(\mathrm{LiPF}_{6}\right)$ dissolved in an appropriate mixture of ethylene carbonate (EC) and propylene carbonate (PC); the polymer-electrolyte interaction would be ensured by the labile hydrogen of $\mathrm{PC}$ and the polar CN groups of PAN (Fig. 4). In addition the solvants EC and PC have a high dielectric constant $\left(\varepsilon^{\prime} r \cong 60\right)$ which will ensure an efficient separation of the $\mathrm{Li}^{+}$cations from the $\mathrm{PF}_{6}^{-}$anions and, therefore, lead to a high room-temperature conductivity. Finally these solvants have a low volatility so that they will allow an easy manufacturing process of the membrane with an accurate control of the ratio EC/PC.

When we started our research on PLR systems, 5 years ago [48], no one, to our knowledge, had used $\mathrm{LiPF}_{6}$ in conjunction with PANPC-EC. The other authors used mainly $\mathrm{LiClO}_{4}$ and $\mathrm{LiAsF}_{6}$ instead of $\mathrm{LiPF}_{6}$ because the $\mathrm{ClO}_{4}^{-}$and $\mathrm{AsF}_{6}^{-}$anions are less easily oxidized than $\mathrm{PF}_{6}^{-}$; therefore the anodic stability of the electrolytes using 


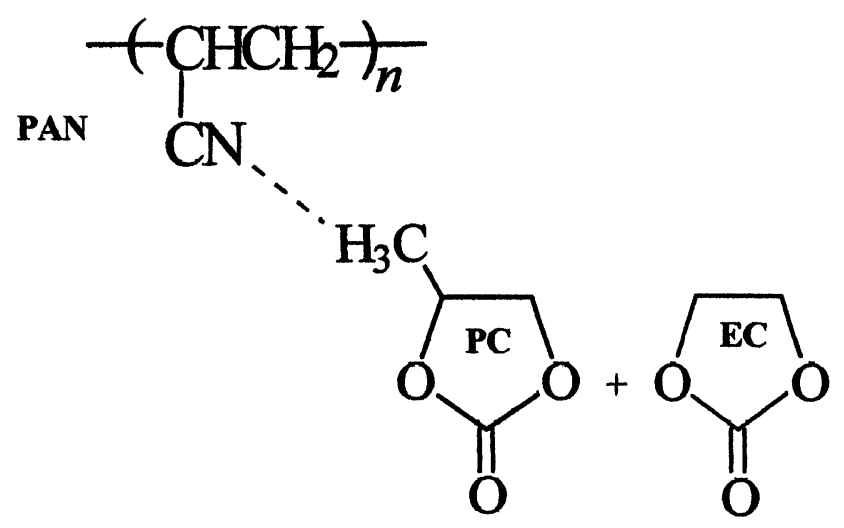

FIGURE 4 Structures of PAN-PC-EC showing the main polymer-solvent interaction.

$\mathrm{LiClO}_{4}$ or $\mathrm{LiAsF}_{6}$ would be greater. However we checked that the oxydation potential of $\mathrm{PF}_{6}^{-}$remained rather high, around $4.3 \mathrm{~V} v s . \mathrm{Li}$ [48]. In fact we have not considered here $\mathrm{LiClO}_{4}$, due to its explosive character in presence of organic solvants, and $\mathrm{LiAsF}_{6}$, due to the toxicity of Arsenic. Moreover the highest cathodic stability was observed for the electrolyte membranes using $\mathrm{LiPF}_{6}$ [48].

\section{b) Manufacturing Process}

The manufacturing process of the polymeric electrolyte membrane is illustrated on Figure 5: the reagents were first mixed at the required mass ratio in the inert atmosphere of a dry box and, then, heated at $110^{\circ} \mathrm{C}$ in order to get a solution of appropriate viscosity which can be easily cast onto the substrate. Membranes having a translucent elastomeric appearance were finally obtained after cooling at room temperature.

\section{c) Main Characteristics}

One easily guesses that the conductivity's of these hybrid electrolytes can be tailored by a judicious selection of the ratio of the different components. 
(1) dissolution of $\mathrm{LiPF}_{6}+\mathrm{EC}+\mathrm{PC}$ at $25^{\circ} \mathrm{C}$; drying $\mathrm{PAN}$ at $60^{\circ} \mathrm{C}(48 \mathrm{hr}$.) under vacuum

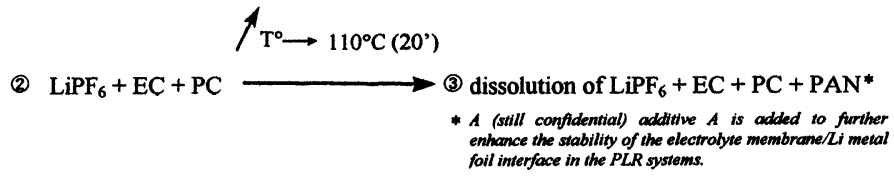

(4) «casting» of the viscous solution

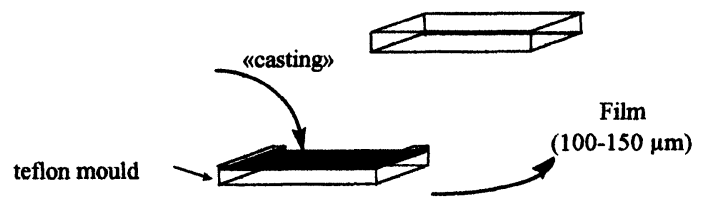

FIGURE 5 Manufacturing process of the electrolyte membrane.

Among the numerous compositions which were studied [48], we established that the highest conductivity was achieved for the composition (molar \%): $20 \mathrm{PAN} / / 5 \mathrm{LiPF}_{6} / 40 \mathrm{EC} / 35 \mathrm{PC}$. The conductivity is indeed close to that of liquid electrolytes (Fig. 6), [48].

Moreover the membrane has the required dimensional stability, with a Young modulus of $\sim 1.7 \mathrm{MPa}$ at $25^{\circ} \mathrm{C}$ [48]. Figure 6 shows that this composition is rather critical: a slight modification of the EC/PC ratio or of the $\mathrm{LiPF}_{6}$ content induces, indeed, a drop of the conductivity, particularly at low temperature. In fact, this drop of the conductivity arises from a crystallization process. The latter is illustrated on Figure 7 which displays the DSC thermograms of various membranes having different proportions of EC and PC.

The peaks A and B which appear only for the membranes 1, 2 and 3 account for a crystallization process (peak A) followed by a melting process of the crystallized species (peak B). It is noteworthy that the membrane 4 which does not undergo any visible crystallization process (Fig. 7) has the highest conductivity reported above (Fig. 6). It corresponds, indeed, to the composition (molar \%): $20 \mathrm{PAN}^{-} / 5 \mathrm{LiPF}_{6} / 40 \mathrm{EC} /$ 35 PC. In fact, the drop of the conductivity observed for the other compositions (Fig. 6), which exhibit the crystallization process evidenced on Figure 7, would imply that the crystallized species involve $\mathrm{Li}^{+}$ions which are trapped in crystallized EC. On the other hand, for the membrane 4 (Fig. 7), having the highest conductivity, all EC interacts efficiently with PC so that no crystallization of EC occurs. The Figure 8 


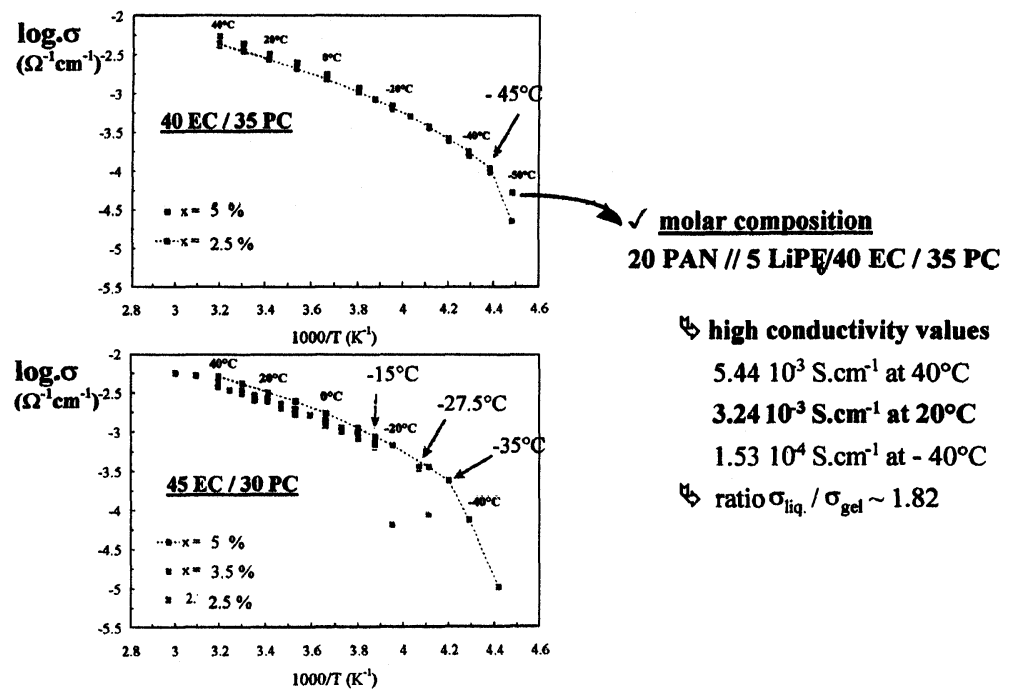

FIGURE 6 Ionic conductivities (Ac measurements) of hybrid electrolyte membranes of composition (molar\%): 20PAN//5LiPF $6 / 75(\mathrm{EC}+\mathrm{PC})$.
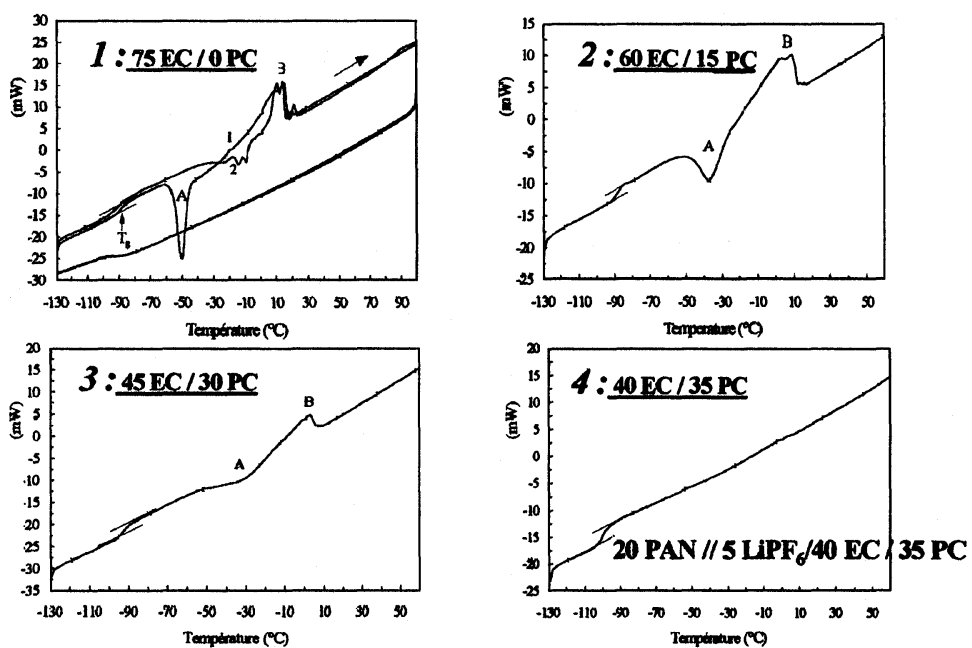

FIGURE 7 DSC thermograms of hybrid electrolyte membranes of composition (molar \%): 20PAN//5LiPF6/75(EC + PC). 




FIGURE 8 Potential sweep, $J=f(E)$, of a stainless steel electrode versus Li metal foil sandwiching the membrane* 4 (see Fig. 7) having the highest conductivity (see Fig. 6). *The additive $A$ (see Fig. 5) is added.

illustrates the rather good electrochemical stability of the membrane 4 ; the electrochemical stability window was determined by running voltammetry sweeps of a stainless steel blocking electrode $v$ s. a lithiumfoil counter-electrode.

The whole results would imply that the membrane 4 could be advantageously used as electrolyte for efficient PLR systems.

\section{Choice, Preparation and Properties of the Cathode Materials}

\section{a) Choice of the Materials}

Commercially available lithium batteries use layered $\mathrm{LiCoO}_{2}$ cathodes [49]. However the high cost and toxicity of cobalt motivate the development of cheaper and non-toxic electrode materials. In this prospect nanocrystalline or/and X-ray amorphous. lithium-manganese oxides are very attractive alternatives [50-53]; moreover these materials can be advantageously prepared at low temperature leading to low-cost manufacturing processes.

Ten years ago, we have indeed shown, using many examples, that the control of crystallite size was a key factor which determine the electrochemical performances of the electrodes. The following "electrochemical model" was deduced [51]:

"Nanocrystalline materials are likely to have an enhanced electrochemical activity, compared with that of their microcrystalline 
homologue, provided that the first electrochemical process which intervenes is a discharge of the Li battery.

The discharge should begin with an electrochemical grafting of the $\mathrm{Li}^{+}$ions at/near the crystallite surface. The structural defects or distorsions at/near the crystallites, which are more obvious in the nanoscale region than in the microscale one, can indeed act as reversible grafting sites for $\mathrm{Li}^{+}$ions.

The following second electrochemical step occurs during the discharge of the Li battery (when the crystallite structure is adapted): intercalation of the $\mathrm{Li}^{+}$ions into the crystallites.

The discharge-charge electrochemical process can be depicted as:

$$
\text { grafting } \rightarrow \text { intercalation } \rightarrow \text { deintercalation } \rightarrow \text { degrafting. }
$$

These concepts are important because they allow to foresee when it is preferable to use nanocrystalline electrode materials (or microcrystalline electrode materials), depending on whether the first electrochemical process of the Li battery is a discharge (or a charge)".

We will illustrate, here, these concepts for two different nanocrystalline electrode materials based on lithium manganese oxide:

(i) nanocrystalline spinel-type " $\mathrm{LiMn}_{2} \mathrm{O}_{4}$ " [48, 52].

(ii) nanocrystalline rock-salt type " $\mathrm{Li}_{2} \mathrm{MnO}_{3}$ " $[50,48]$.

\section{b) Synthesis Process}

(i) The nanocrystalline spinel electrode prepared at $200^{\circ} \mathrm{C}$

An original polymeric route, that we have recently patented [53], has been used. It is depicted on Figure 9.

Homogeneous starting materials have been obtained from an aqueous $\mathrm{HNO}_{3}$ (1N) solution into which was added appropriate amounts of polyacrylamide (PAam, Aldrich M.W. = 10.000), lithium carbonate (Aldrich 99,997\%) and manganese (II) acetate tetrahydrate (Aldrich $99+\%$ ). First of all a gel is formed and afterwards a xerogel (hybrid polymer) after removal of the solvent. The controlled explosive oxydo-reduction reaction, - occurring at $\sim 200^{\circ} \mathrm{C}$ under oxygen atmosphere (Fig. 9)-, of the hybrid polymer leads to ultrafine crystallites $(\sim 50 \AA)$ of the spinel phase of composition $\mathrm{Li}_{1-3 \delta} \square 3 \delta$ $\left[\mathrm{Mn}_{2-2 \delta}^{3,552} \mathrm{Li}_{2 \delta}\right]^{\text {oct }} \mathrm{O}_{4}$ with $\mathrm{S} \cong 0.02[48,53]$. The later was deduced from 


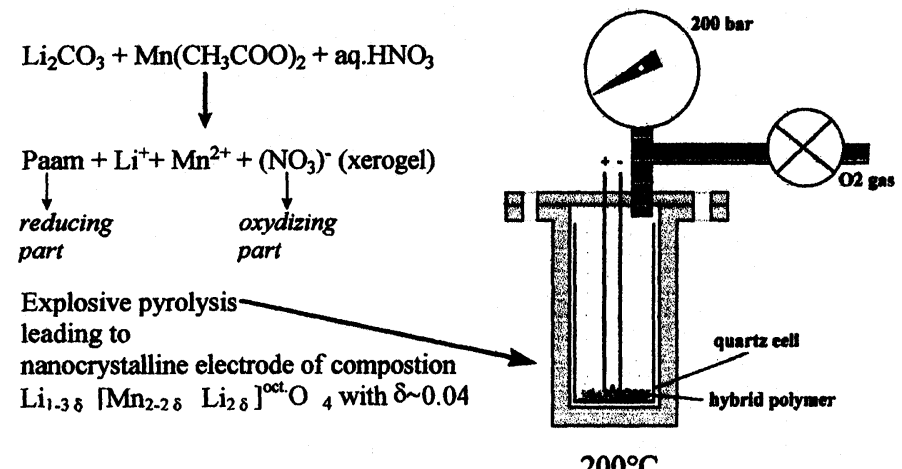

FIGURE 9 Manufacturing process of the nanocrystalline $\mathrm{LiMn}_{2} \mathrm{O}_{4}$ electrodes.

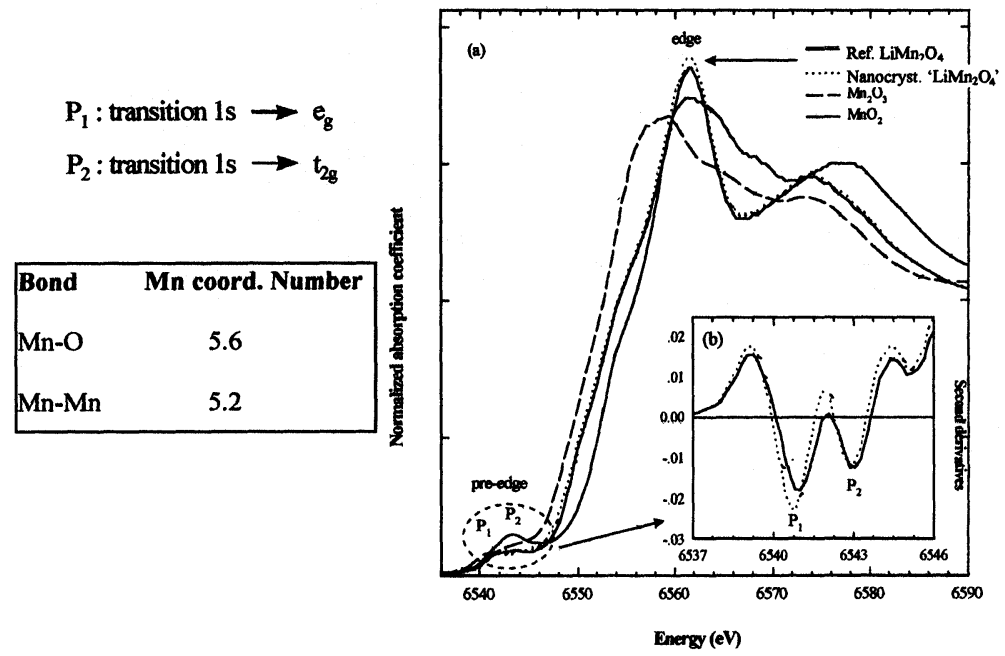

FIGURE 10 The average oxidation state of $\mathrm{Mn}$, which is higher than 3.5 , and the $\mathrm{Mn}-\mathrm{O}, \mathrm{Mn}-\mathrm{Mn}$ coordination numbers, which are lower than 6, observed for the nanocrystalline ' $\mathrm{LiMn}_{2} \mathrm{O}_{4}$ ' have been deduced from XAS analysis. They were correlated to the higher structural disorder which is characteristic of the nanocrystalline texture [52]. For instance, this figure shows the XANES (Mn K edge) spectra for the nanocrystalline ' $\mathrm{LiMn}_{2} \mathrm{O}_{4}$ '.

the combination of chemical titration, XPS analysis [48] and XAS analysis [52], (Fig. 10). The TEM micrographs (Fig. 11) and XRD pattern (Fig. 12) are characteristic of the nanocrystalline texture with an average crystallite size of $50 \AA$. 


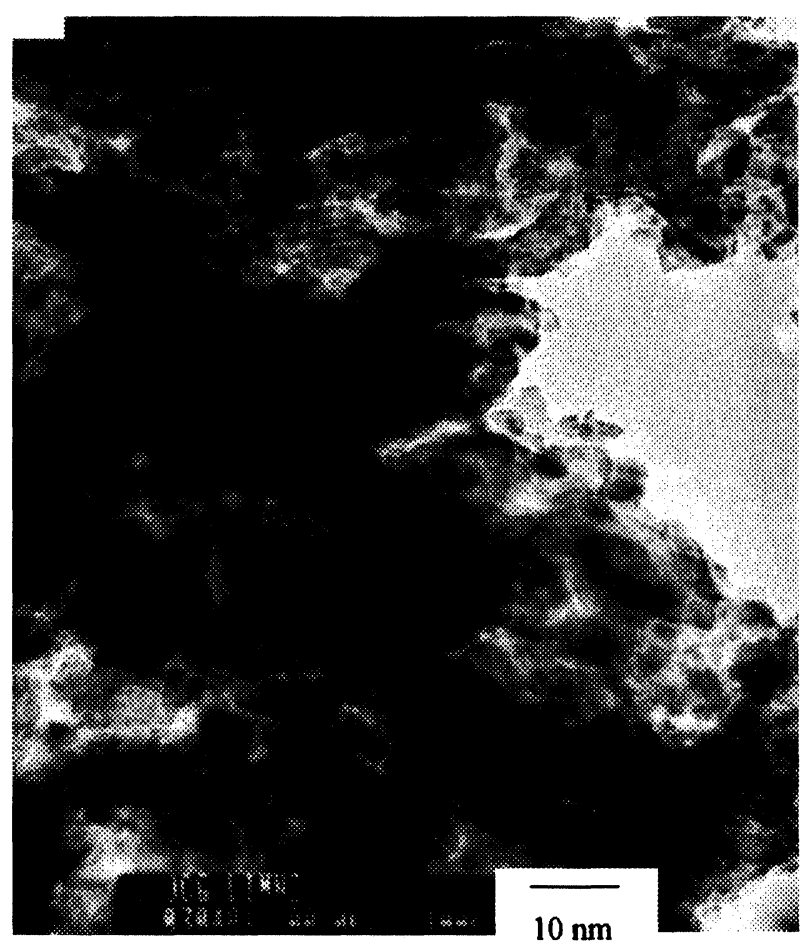

FIGURE 11 TEM micrograph of nanocrystalline ' $\mathrm{LiMn}_{2} \mathrm{O}_{4}$ '. The average crystallite size is $\sim 50 \AA$.

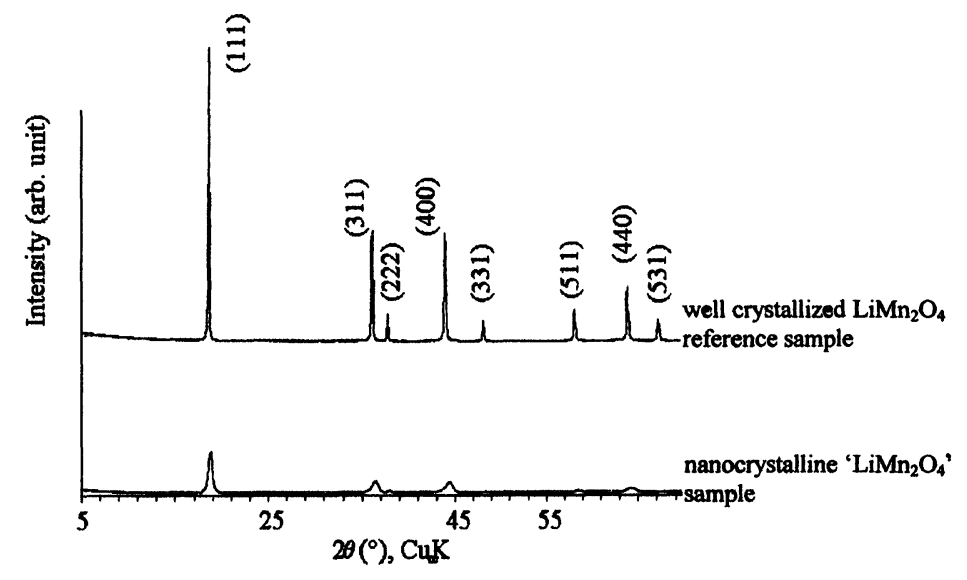

FIGURE 12 X-ray diffraction pattern characteristic of the nanocrystalline structure of ' $\mathrm{LiMn}_{2} \mathrm{O}_{4}$ '. 
(ii) The nanocrystalline rock-salt type electrode prepared at $\sim$ room temperature

As quoted by Kim J. and Manthiram A; [50], complex metal oxides are usually prepared by firing of the raw materials at elevated temperature. This approach cannot yield to the accessibility of metastable nanocrystalline or/and X-ray amorphous phases which may be highly attractive as electrode materials for lithium batteries according to Ref. $[50,51,52,54]$, and also according to the above quoted "electrochemical model".

Here we have used $\mathrm{LiI}$ to reduce the permanganate ion $\left(\mathrm{Mn}^{\mathrm{VII}} \mathrm{O}_{4}^{-}\right)$ in $\mathrm{Na}^{+}$containing aqueous medium [50] in order to produce a $\mathrm{Mn}^{\mathrm{IV}}$ rich nanocrystalline oxide of composition close to $\mathrm{Li}_{2} \mathrm{MnO}_{3}$. The detailed preparation process is illustrated on Figure 13.

The as-prepared sample was found to be amorphous to X-ray diffraction as similarly observed by Kim, J. and Manthiram, A. The detailed textural and structural investigation using XPS, XAS, TEM, $\mathrm{XRD}$ etc ... analysis is currently in progress and will be reported later on [55].

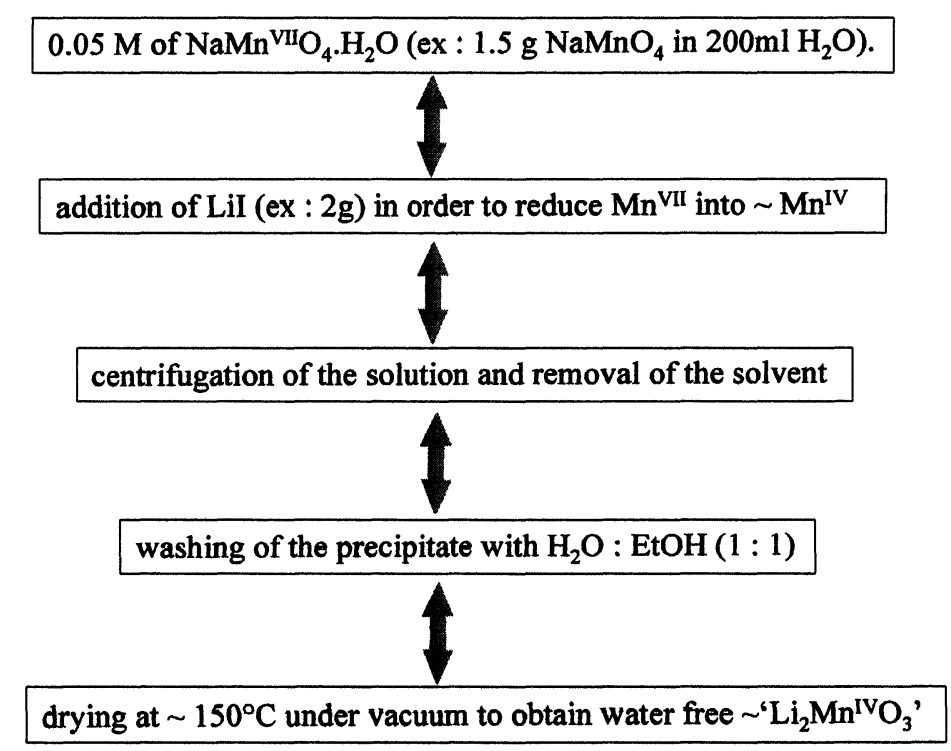

FIGURE 13 Synthesis process of the nanocrystalline rock-salt type ' $\mathrm{Li}_{2} \mathrm{Mn}^{\mathrm{IV}} \mathrm{O}_{3}$ '. 


\section{ELECTROCHEMICAL PROPERTIES OF THE PLR BATTERIES}

The electrochemical measurements were performed using a computercontrolled potentiostat/galvanostat (Tacussel, PGS 201T model) for the PLR cells assembled by sandwiching the polymer electrolyte (membrane 4 in Fig. 7) between the lithium anode foil and the composite cathode.

The composite cathode was made according to the preparation procedure proposed by us $[48,53]$ and that proposed by Sun, Y. K. and Jin, S. H. for their efficient PLR cells [56].

The as synthesized nanocrystalline " $\mathrm{LiMn}_{2} \mathrm{O}_{4}$ " (or " $\mathrm{Li}_{2} \mathrm{MnO}_{3}$ ") powder was added to PAN solution in demethyl sulfoxide (DMSO) as a solvent. The slurry was spread onto a carbone active tissue of $\sim 2000$ $\mathrm{m}^{2} / \mathrm{g}$ surface area (Actitex) and dried under vacuum for $16 \mathrm{~h}$ at $110^{\circ} \mathrm{C}$. The dried composite cathode was then compressed with a roll presser in the inert atmosphere of a dry box.

The PLR cells were assembled, in the dry box, by sandwiching the above mentioned membrane 4 (see Fig. 7) between a lithium foil and the composite cathode.

The electrochemical measurements were performed using computercontrolled potentiostat/galvanostat (Tacussel, PGS 201T model). The cells based on nanocrystalline " $\mathrm{LiMn}_{2} \mathrm{O}_{4}$ " and on nanocrystalline " $\mathrm{Li}_{2} \mathrm{MnO}_{3}$ " were cycled between cut-off voltages of $2.2-3.2 \mathrm{~V}_{\mathrm{Li} / \mathrm{Li}+}$ and of $2-4 \mathrm{~V}_{\mathrm{Li} / \mathrm{Li}+}$ respectively at a current density of $1 \mathrm{~mA} . \mathrm{cm}(\mathrm{C} / 5)$.

The reversible capacity corresponds to $\sim 0.8$ mole of $\mathrm{Li}$ per mole of electrode material as shown on the Figures 14 and 15. This rather high and reversible capacity was related to the presence of the structural defects arising from the nanoscale structure, in agreement with the "electrochemical model" mentioned above. The influence of the structural defects has been investigated recently using XAS or Li NMR [52] and also the evolution of the open circuit voltage of the cell as a function of the inserted $\mathrm{Li}$ [48].

In conclusion, the PLR batteries based on the electrolyte membrane of composition (molar \%): $20 \mathrm{PAN} / / 5 \mathrm{LiPF}_{6} / 40 \mathrm{EC} / 35 \mathrm{PC}$, sandwiched between a $\mathrm{Li}$ foil and nanocrystalline " $\mathrm{LiMn}_{2} \mathrm{O}_{4}$ " or " $\mathrm{Li}_{2} \mathrm{MnO}_{3}$ " composite cathode appears to be highly attractive for industrial point of view, although further investigation is needed. 


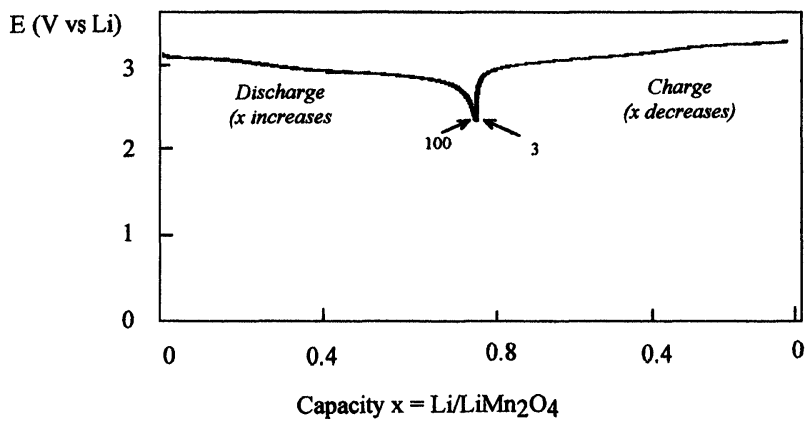

FIGURE 14 Discharge/charge behavior (C/5) with the number of cycles for the PLR cells using nanocrystalline ' $\mathrm{LiMn}_{2} \mathrm{O}_{4}$ '.

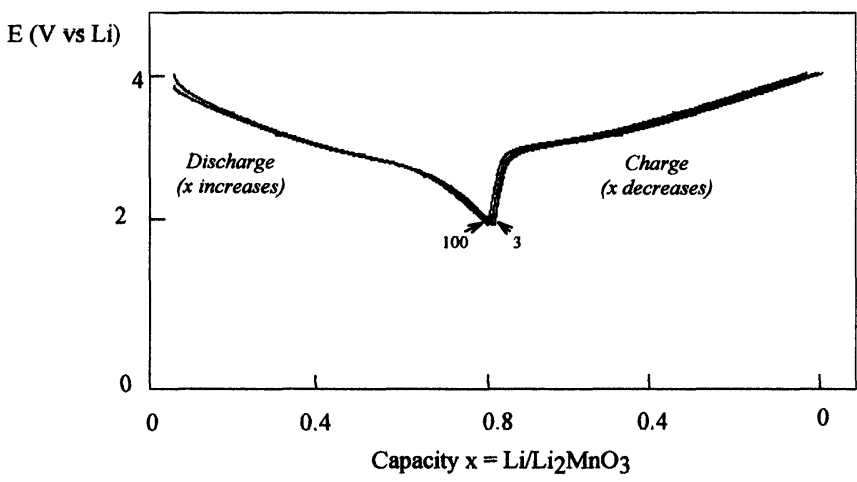

FIGURE 15 Discharge/charge behavior (C/5) with the number of cycles for the PLR cells using nanocrystalline ' $\mathrm{LiMn}_{2} \mathrm{O}_{3}$ '.

\section{References}

[1] Megahed, S. and Scrosati, B. (winter 1995). The Electrochemical Society Interface, winter 1995, pp. 35-37.

[2] Henricksen, G. L., De Luca, W. H. and Vissers, D. R. (1994). Chemtech, pp. 32-35.

[3] Cairns, E. J. (1992). Interface, 1, 24-26.

[4] Commission of the European Communities, Joule II-Programme, Energy Conservation and Utilization, Brussels.

[5] Ishikawa, R., Hazama, T., Mivabashi, M. and Andoh, H. (1995). Proceedings of the International Workshop on Advanced Batteries, Osaka, Japan, pp. 22-24.

[6] Rouxel, J. (1980). Physica, 99B, 3-6.

[7] Armand, M. (1978). Doctoral Thesis, Inst. National Polytech. de Grenoble.

[8] Delmas, C., Fouassier, C. and Hagenmuller, P. (1978). J. Phys. Chem. Solids, 39, 55-61. 
[9] Molenda, J. (1986). Solid State Ionics, 21, 263-269.

[10] Levasseur, A. and Menetrier, M. (1989). Mat. Sci. Eng., B3, 5-10.

[11] Takehara, Z. I. and Kanamura, K. (1993). Electrochemica Acta., 38, 1169-1173.

[12] Abraham, K. M. (1993). Electrochemica Acta, 38, 1233-1238.

[13] Broussely, M., Perton, F., Labat, J., Staniewicz, R. and Romero, A. (1993). J. Power Sources, 43-43, 209-214.

[14] Nagaura, T. (1990). Proceedings of the 4th International Rechargeable Battery Seminar, Deerfield Beach, Florida, U.S.A.

[15] Dahn, J. R., Von Sacken, V. and Fong, R. (1990). Proceedings of the 178th Meeting of the Electrochemical Society, Seattle, Washington, U.S.A.

[16] Koetschau, I., Richard, M. N., Dahn, J. R., Soupart, J. B. and Rousche, J. C (1995). J. Electrochemical Soc., 142(9), 2906-2910.

[17] Progress in batteries and Battery Materials (1995). Vol. 14. Edited by Ralph J. Brodd, ITE-JEC Press Inc.

[18] Lithium Battery: New Materials, Development and Perspectives (1994). Edited by Pistoia, G., Elsevier Science B.V.

[19] Goodenough, J. B., Thackeray, M. M., David, W. I. F. and Bruce, P. G. (1984). Revue de Chimie Minérale 21, pp. 435-441.

[20] Gummow, R. J., de Kock, A. and Thackeray, M. M. (1994). Solid State Ionics, 69 , $59-62$.

[21] Tarascon, J. M. (1995). US Patent 5, 424, 205-209.

[22] Kokband, R. and Barker, J. (1996). Solid State Ionics, 84, 1-5.

[23] Ohzuku, T., Kitawaga, M. and Hirai, T. (1990). J. Electrochem. Soc., 137, 769-772.

[24] Tarascon, J. M., Wang, E., Shokoohi, F. K., McKinnon, W. R. and Colson, S. (1991). J. Electrochem. Soc., 138, 2859-2864.

[25] Manev, V., Momchilov, A., Nassalevska, A. and Sato, A. (1995). J. Power Sources, 54, 323-327.

[26] Jiang, Z. and Abraham, K. M. (1996). J. Electrochem. Soc., 143, 1591-1593.

[27] Barboux, P., Tarascon, J. M. and Shokoohi, F. K. (1991). J. Solid State Chem., 94, $185-189$.

[28] Huang, H. and Bruce, P. G. (1994). J. Electrochem. Soc., 141, L106.

[29] Liu, W., Farrington, G. C., Chaput, F. and Dunn, B. (1996). J. Electrochem. Soc., $143,879-882$.

[30] Linden, D. (1995). Handbook of Batteries, 2nd edn., Wiley, New York.

[31] The fuel cell technology also offers a solution to the problem of the damaging health and environmental effects of releasing nauseous gases into the atmosphere, in the form of a clean, zero-emission option for both the transportation and power generation industries (see for instance the article of Mike Lain from AEA technology in UK: "Membrane fuel cells provide a breath of fresh air": Membrane Technology No. 87).

[32] Bruce, P. G. (1996). Philos. Trans. R. Soc. London, Ser. A., 354, 1577-1580.

[33] Scrosati, B. (1992). J. Electrochem. Soc., 139, 2276-2280.

[34] Tarascon, J. M. and Guyomard, D. (1992). J. Electrochem. Soc., 139, 937-941.

[35] Passerini, S., Rosolen, M. and Scrosati, B. (1993). J. Power Sources, 45, 333-338.

[36] Armand, M. B., Chabagno, J. M. and Duclot, M. (1978). 2nd Int. Meet. Solid Electrolytes, St. Andrews, Scotland, U.K., Sept. 20-22.

[37] Gray, F. M. (1991). Solid Polymer Electrolytes, VCH, New York.

[38] Gauthier, M., Fauteux, D., Vassort, G., Belanger, A., Duval, M., Ricoux, P., Chabagno, J. M., Muller, D., Rigaud, P., Armand, M. and Peroo, D. (1985). J. Electrochem. Soc., 132, 1333-1340.

[39] Armand, M., Gorecki, W. and Andreani, R. (1989). Proc. 2nd Int. Symp. Polymer Electrolytes, Siena, Italy, June 14-16, Ext. Abstr.

[40] Croce, F., Brown, S. D., Greenbaum, S. G., Slane, S. M. and Salom, M. (1993). Chem. Mater., 5, 1268-1272. 
[41] Bohnke, O., Rousselot, C., Gillet, P. A. and Truche, C. (1992). J. Electrochem. Soc., 139, 1862-65.

[42] Watanabe, M., Kanba, M., Nagaoka, K. and Shinohara, I. (1983). J. Polym. Sci., Polym. Phys. Ed., 21, 939-945.

[43] Abraham, K. H. and Alamgir, M. (1990). J. Electrochem. Soc., 106, 1657-1660.

[44] Schmutz, C., Tarascon, J. M., Gozdz, A. S., Warren, P. C. and Shokoohi, F. K. (1994). Rechargeable Lithium and Lithium-Ion Batteries, Megahed, S., Barnett, B. M. and Xie, L. Editors, PV 94-28, pp. 330-333. The Electrochemical Society Proceedings Series, Pennington, N.J.

[45] Alamgir, M. and Abraham, K. M. (1995). J. Power Sources, 54, 40-44.

[46] Rosanski, H. G. and Irving, I. D. (1994). Electronic Engineering Times, May 23.

[47] Tarascon, J. M., Gozdz, A. S., Schmutz, C., Shokoohi, F. and Warren, P. C. (1996). Solid State Ionics, 86-88, 49-54.

[48] Treuil, N. (1998). Ph.D. Thesis, Univ. Bordeaux I, France.

[49] Nagura, T. and Tozawa, K. (1990). Prog. Batteries Sol. Cells, 9, 209-1217.

[50] Kim, J. and Manthiram, A. (1997). Nature, 390, 265-267.

[51] Campet, G., Treuil, N., Deshayes, A., Frison, J. C., Portier, J. and Rabardel, L. (1998). Active and Passive Elec. Comp., 21, 167-181, and references therein.

[52] Treuil, N., Hwang, S. J., Campet, G., Portier, J., Labruyere, C., Menetrier, M. and Choy, J. H. (1999). J. Phys. Chem. B., 103(12), 2100-2106.

[53] Treuil, N., Portier, J., Campet, G. and Frison, J. C. (1996). CNET patent $\mathrm{n}^{\circ} 9612690$.

[54] Stein, A., Keller, S. W. and Malbouk, T. E. (1993). Science, 259, 1558-1564.

[55] Hwang, S. Y., french-corean Ph.D. Thesis, Univ. Bordeaux I, in preparation.

[56] Sun, Y. K. and Jin, S. H. (1998). J. Mater. Chem., 8(11), 2399-2404. 

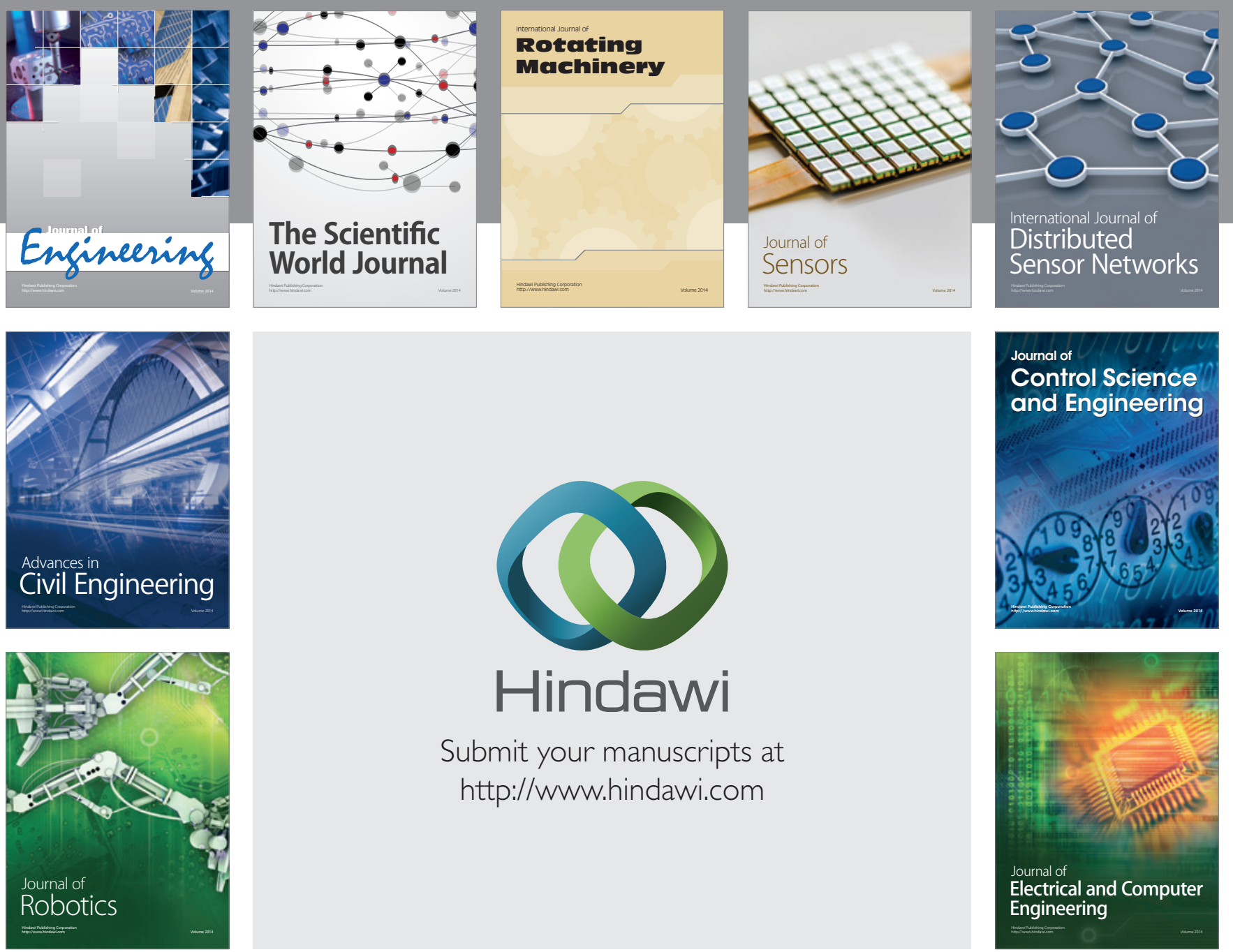

Submit your manuscripts at

http://www.hindawi.com
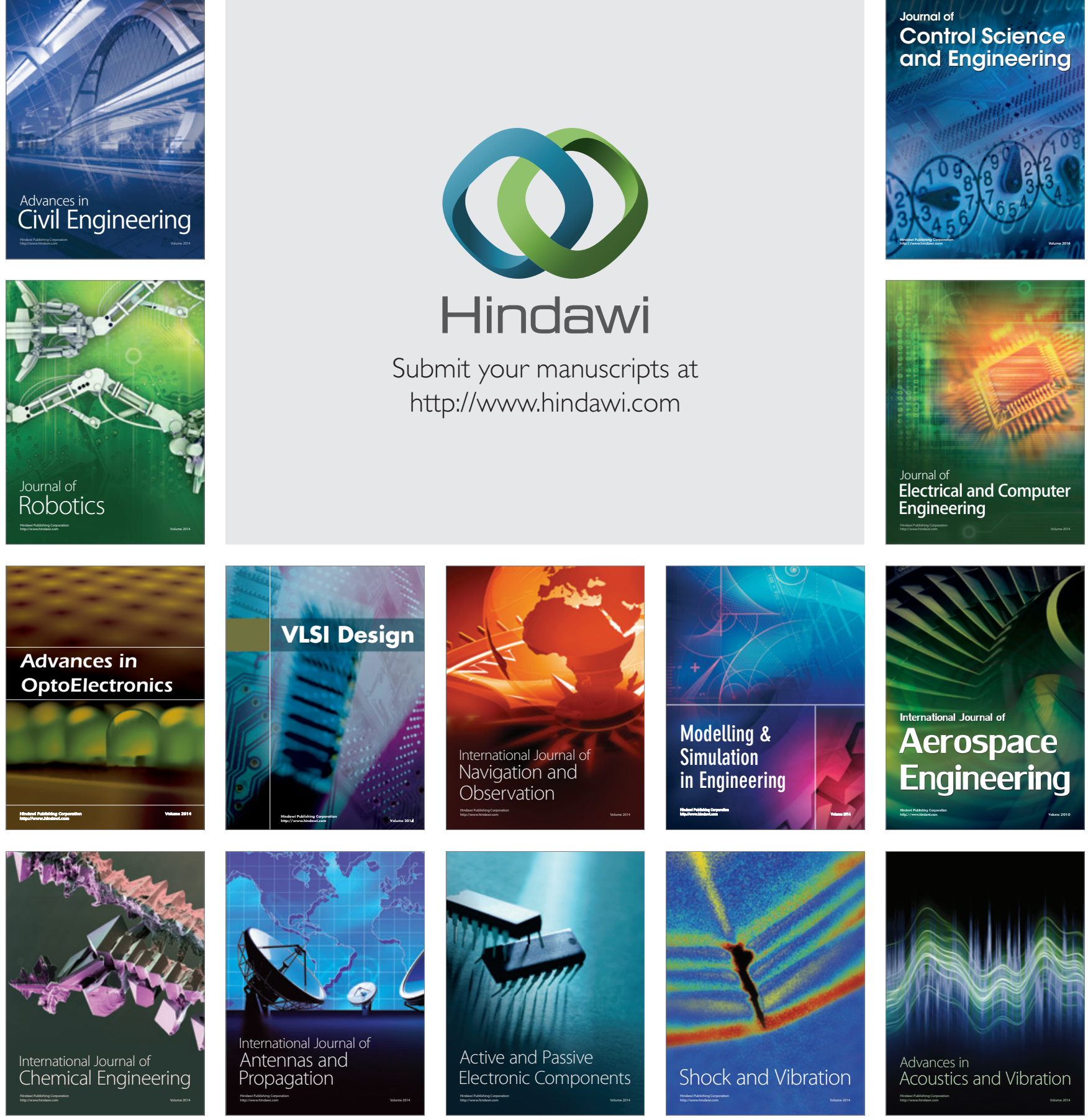